\title{
Effects of maternal undernutrition during early pregnancy on apoptosis regulators in the ovine fetal ovary
}

\author{
R G Lea ${ }^{1}$, L P Andrade ${ }^{2}$, M T Rae ${ }^{3}$, L T Hannah ${ }^{1}$, C E Kyle ${ }^{4}$, J F Murray ${ }^{5}$, S M Rhind ${ }^{4}$ \\ and D W Miller ${ }^{6}$ \\ ${ }^{1}$ Rowett Research Institute, Greenburn Road, Bucksburn, Aberdeen, AB21 9SB, UK, ${ }^{2}$ Escola Superior Agrária \\ Castelo Branco, UD Zootecnia, Castelo Branco, Portugal, ${ }^{3}$ University of Edinburgh, Department of Obstetrics and \\ Gynaecology, Edinburgh, UK, ${ }^{4}$ Macaulay Land Use Research Institute, Craigiebuckler, Aberdeen, UK, \\ ${ }^{5}$ Departments of Basic Medical Sciences and Clinical Development Sciences, St George's Hospital Medical \\ School, London SW17 ORE, UK and ${ }^{6}$ Scottish Agricultural College, Sustainable Livestock Systems Group, \\ Aberdeen, UK
}

Correspondence should be addressed to R G Lea; Email: R.Lea@rowett.ac.uk

\begin{abstract}
This study aimed to determine whether reduced fetal ovary folliculogenesis in ewes undernourished during early/midpregnancy is associated with altered ovarian cell proliferation and/or the expression of apoptosis-regulating genes. Groups of ewes $(n=11-19)$ were fed either $100 \%$ (high; H) or $50 \%$ (low; L) of metabolisable energy requirements for live-weight maintenance during selected windows of gestation. All animals were killed at days 50, 65 or 110 of gestation. Between mating and slaughter, control animals were fed the $\mathbf{H}$ ration, while animals of other subgroups were fed the $\mathbf{L}$ ration from (a) mating to slaughter at 50, 65 or 110 days; (b) 0 to 30 days; (c) 31 to 50 or 65 days; or (d), in the day 110 slaughter group only, from 66 to 110 days. Bouin's-fixed fetal ovaries were examined for (a) Ki67 immunoexpression (proliferation) and (b) Bax and Mcl-1 (apoptosis-regulating genes) expression by in situ hybridisation (day 110) and immunohistochemistry (days 50, 65 and 110). At day 50, maternal nutrition had no effect on Ki67, predominant in germ cells, or Bax and Mcl-1, predominant in the oocytes. Restricted maternal food intake from 0 to 30 days significantly reduced staining for Ki67 in germ cells at day 65 $(P<0.05)$ but increased staining in granulosa cells at day $110(P<0.05)$. In animals fed the $L$ ration for 110 days, primordial follicle Bax and Mcl-1 were significantly increased (Bax: $P<0.01 ;$ Mcl-1: $P<0.05$ ). Granulosa cell Bax was also increased $(P<0.05)$. When the $L$ ration was fed from 66 to 110 days, granulosa cell Bax $(P<0.05)$ and primordial follicle Mcl-1 $(P<0.01)$ were also significantly increased. In the fetal ovarian vasculature, animals underfed for $0-110$ days had significantly elevated perivascular Mcl-1 $(P<0.001)$ and endothelial Bax expression $(P<0.05)$. Moreover, at day 110, endothelial Mcl-1 was increased by underfeeding from 0 to 30 days $(P<0.05)$. These data indicate that maternal undernutrition alters proliferation and the expression of apoptosis-regulating genes in the developing fetal ovary. The precise mechanism depends on the window of maternal food restriction.

Reproduction (2006) 131 113-124
\end{abstract}

\section{Introduction}

Maternal undernutrition before or during pregnancy, or during the postnatal period, can adversely affect fetal and neonatal gonad development (Rae et al. 2001, Rhind 2004). Moreover, in rodents (Meikle \& Westberg 2001), sheep (Rae et al. 2002) and man (lbanez et al. 2002), restricted maternal nutrition during pregnancy has been reported to reduce ovulation rates in adult female offspring, suggesting that restricted fetal growth in response to undernutrition, in utero, can have long-term adverse effects on adult human reproductive health and farm animal productivity.
Using a sheep model, Rae et al. (2001) reported that restricted food intake during the first 110 days of pregnancy (term $=147$ days) delays fetal ovarian folliculogenesis. Intriguingly, limiting the period of restriction to each one of three windows of 1-2 months during the first 110 days of gestation also reduced the numbers of follicles developing beyond the primordial stage irrespective of the time at which the restriction was applied (Rae et al. 2001). Since the fetal ovaries were at different stages of development during each of these windows, these findings indicate that many different mechanisms underlie nutrition-mediated changes in ovarian development. 
The number of oocytes in the fetal ovary, which dictates the longevity of adult female fertility, is determined by midgestation in man (Baker 1963). Thus, the mechanisms that control follicle development during this period control adult reproductive function. In the developing fetal ovary, the mechanisms that regulate cellular proliferation and apoptosis control germ-cell numbers and follicular atresia (Hsueh et al. 1994). It follows, therefore, that the effects of nutritional restriction in early pregnancy in the sheep may affect ovarian development through alteration of these processes. In support of this, recent studies have shown that food-intake restriction of pregnant ewes from mating to midgestation (day 78) increases DNA damage in the fetal oogonia (Murdoch et al. 2003). This was accompanied by increased immunoexpression of p53 (cell-cycle arrest gene), $\mathrm{Bcl}-2$ (antiapoptosis gene product) and the base excision repair polymerase B. Murdoch et al. (2003) proposed that the nutrition-induced DNA damage of the oogonia may be counteracted by molecular response mechanisms which induce cell-cycle arrest (p53), inhibit apoptosis (Bcl-2) and thus allow time for DNA repair (polymerase $B$ ).

A number of other regulatory genes are known to be important in adult and fetal ovary development, many of which are members of the $\mathrm{Bcl}-2$ family. The products of these genes exhibit either prosurvival or proapoptotic activity. The products combine to form homo- and heterodimers which are mutually antagonistic; therefore, cell death or survival is determined by the ratio of these factors. In the human fetal ovary, $\mathrm{Bcl}-2$ family members are differentially expressed by different cell types. The antiapoptotic factor $\mathrm{Mcl}-1$ is expressed in the developing follicle throughout gestation and is considered to have an important developmental role. Its antagonist, Bax, is also expressed in the fetal ovary, where it is predominantly localised to somatic and germ cells (Hartley et al. 2002); its involvement in the development process is indicated by the fact that Bax knockout mice exhibit unusual, atretic follicles with excess granulosa cells (Knudson et al. 1995). While Mcl-1 deficiency causes peri-implantation lethality, Bcl-2 knockout mice have reduced numbers of primordial follicles, many of which have abnormal morphology (Ratts et al. 1995, Rinkenberger et al. 2000). It is clear therefore that these genes are fundamentally involved in the control of fetal ovary development.

In this study, sheep subjected to restricted food intake during early pregnancy were used to investigate mechanisms through which a reduction in folliculogenesis in the early to midgestation fetal ovary may be induced. It was postulated that this might be mediated by changes in apoptosis-regulating genes that alter subsequently the balance of apoptosis and proliferation in the developing follicles and surrounding ovarian cells. Specifically, we investigated the effects of restricted food intake on (a) ovarian Ki67 immunostaining (marker of proliferation) and (b) the expression of the apoptosis regulatory genes Mcl-1 and Bax.

\section{Materials and Methods}

\section{Animal management and nutritional treatments}

All experimental procedures have been described elsewhere (Rae et al. 2001). In brief, experiments involving live animals were conducted under the authority of the UK Animals (Scientific Procedures) Act 1986, after Home Office and local ethics committee approval (Macaulay Land Use Research Institute, Aberdeen, UK). Mature Scottish Blackface ewes were fed to achieve a similar, moderately high body condition before mating. All ewes were mated at a synchronised oestrus after treatment, for 14 days, with intravaginal progestagen pessaries (Chronolone, 30 mg; Intervet, Cambridge, UK).

Animals were fed rations estimated to supply either the metabolisable energy (ME) requirements of a pregnant ewe (high; H), or $50 \%$ of that amount (low; L), amounts being adjusted according to stage of pregnancy and treatment group (Robinson et al. 1983). The diet consisted of pelleted feed (Green Keil, North Eastern Farmers Ltd, Aberdeen, UK) and hay that provided, initially, $8 \mathrm{MJ} \mathrm{ME}$ per day $(\mathrm{H})$ or $4 \mathrm{MJ}$ ME per day $(\mathrm{L})$. From the time of mating onward, sheep were housed individually under natural lighting conditions and had free access to water. Ewes were scanned by ultrasonography at day 80 of gestation to determine the numbers of fetuses, and rations were then increased, as necessary, to maintain the same differential nutritional states while the fetal burdens were increasing (Robinson et al. 1983). At the time of mating, ewes were allocated randomly within body condition score class (range 2.25-3.00, on a scale of 0-5) (Russel et al. 1969) to one of four or five nutritional treatment groups, depending on the time of slaughter.

\section{Slaughter group 1 (50 days)}

Ewes (15-19 per group), with a mean live weight ( \pm S.E.M.) of $59.0 \pm 0.62 \mathrm{~kg}$ and a mean condition score of $2.5 \pm 0.02$ at mating, were housed and fed in individual pens as follows:

- $\mathrm{HH}$ - live-weight maintenance ration (100\% M) from mating to day 50 of gestation

- $\mathrm{LH}-50 \% \mathrm{M}$ from mating to day 30 of gestation and then $100 \% \mathrm{M}$ from day 31 to 50 of gestation

- $\mathrm{HL}-100 \% \mathrm{M}$ from mating to day 30 of gestation and then $50 \% \mathrm{M}$ from day 31 to 50 of gestation

- LL - 50\% M from mating to day 50 of gestation

All ewes were killed at day 50 of gestation.

\section{Slaughter group 2 (65 days)}

Ewes (12-13 per group), with a mean live weight ( \pm S.E.M.) of $58.7 \pm 0.82 \mathrm{~kg}$ and a mean condition score of $2.4 \pm 0.03$ at mating, were housed and fed in individual pens according to the same regimen as slaughter group 1 , except that ewes were killed at day 65 instead of day 50 
of gestation. The second treatment window of each group was extended accordingly.

\section{Slaughter group 3 (110 days)}

Ewes (11-19 per group), with a mean live weight ( \pm S.E.M.) of $59.3 \pm 0.74 \mathrm{~kg}$ and a mean condition score of $2.5 \pm 0.02$ at mating, were treated according to the regimens described for slaughter group 2, except that they were killed at day 110 of gestation. A third period of undernutrition was applied to an additional group at days 66-110 of gestation. The five groups of animals therefore comprised the following:

- $\mathrm{HHH}$ (controls) - live-weight maintenance ration from mating to 110 days of gestation

- $\mathrm{LHH}-\mathrm{L}$ ration from mating to day 30 and then $\mathrm{H}$ ration from day 31 to 110 of gestation

- $\mathrm{HLH}-\mathrm{H}$ ration from mating to day 30 of gestation, $\mathrm{L}$ ration from day 31 to 65 , and $\mathrm{H}$ ration from day 66 to 110 of gestation

- $\mathrm{HHL}-\mathrm{H}$ ration from mating to day 65 and $\mathrm{L}$ ration from day 66 to 110 of gestation

- LLL - L ration from mating to slaughter at day 110 of gestation.

\section{Tissue collection and processing}

Ewes bearing twin or single fetuses were killed with a lethal dose of barbituate anaesthetic (Euthatal: $500 \mathrm{mg} / \mathrm{ml}$, $30 \mathrm{ml}$, i.v.; Rhone Merieux, Harlow, UK). Female fetuses were recovered and weighed. Fetal ovaries were removed, weighed and immersion-fixed in Bouin's solution for $5.5 \mathrm{~h}$. Ovaries were then rinsed and stored in 70\% ethanol before being dehydrated, cleared and embedded in paraffin wax by standard methods, sectioned to $5 \mu \mathrm{m}$, and mounted on poly-L-lysine-coated glass slides before immunohistochemical analysis. In all three slaughter groups, discrepancies between the number of ewes/fetuses in each group were attributable to the fact that there was no control over the numbers of male and female fetuses present at slaughter.

\section{In situ hybridisation}

As previously described (Lea et al. 2005), riboprobes were generated from pCRII-Topo plasmids containing cDNA fragments specific for ovine Mcl-1 and Bax (accession nos. AF144097 and AF163774 respectively) (Lea et al. 2005). The plasmids were linearised with BamH1 or EcoRV for transcription with T7 or Sp6 RNA polymerase to generate anti-sense and sense probes respectively. Probes were radioactively labelled with ${ }^{35} \mathrm{~S}$ with a commercially available kit (Promega).

Briefly, paraffin sections of $5 \mu \mathrm{m}$ were dewaxed with xylene and rehydrated through a decreasing ethanol series. Slides were then washed in DEPC-treated water (5 min) and immersed in $0.1 \mathrm{M} \mathrm{HCl}$ for $20 \mathrm{~min}$ followed by $2 \times$ SSC (saline-sodium citrate buffer) for $30 \mathrm{~min}$ at room temperature. Sections were then exposed to $2.0 \mu \mathrm{g} / \mathrm{ml}$ proteinase $\mathrm{K}$ in $0.2 \mathrm{M}$ Tris- $\mathrm{HCl}(\mathrm{pH} 7.6)$ and $0.05 \mathrm{M}$ EDTA (ethylenediaminetetraacetic acid), at $37^{\circ} \mathrm{C}$ for $20 \mathrm{~min}$, and postfixed in $0.4 \%$ paraformaldehyde in PBS for $20 \mathrm{~min}$ at $40^{\circ} \mathrm{C}$. After two further 5-min washes in PBS, sections were acetylated by immersion in $0.25 \%$ acetic anhydride in $0.1 \mathrm{M}$ triethanolamine for $10 \mathrm{~min}$, washed in $2 \times$ SSC, dehydrated through an ascending ethanol series and left to air dry. Sections were hybridised with $10^{6}$ c.p.m. ${ }^{35} \mathrm{~S}-\mathrm{RNA}$ in $60 \mu \mathrm{l}$ hybridisation buffer at $59^{\circ} \mathrm{C}$ overnight. Next day, sections were washed in $4 \times$ SSC for $4 \times 5 \mathrm{~min}$, incubated in ribonuclease $A$ (Sigma) solution $(0.02 \mathrm{mg} / \mathrm{ml}$ in $0.01 \mathrm{M}$ Tris $-\mathrm{HCl}, 0.5 \mathrm{M}$ $\mathrm{NaCl}$ and $0.001 \mathrm{M}$ EDTA $(\mathrm{pH} \mathrm{7.6)})$ for $30 \mathrm{~min}$ at $37^{\circ} \mathrm{C}$, and washed in $2 \times$ SSC-DTT (SSC with $1 \mathrm{mM}$ DTT (dithiothreitol) (Sigma)) for $2 \times 5 \mathrm{~min}$. Slides were immersed in $1 \times$ SSC-DDT for $10 \mathrm{~min}$ and $0.5 \times$ SSC-DTT for $10 \mathrm{~min}$, and washed at $60^{\circ} \mathrm{C}$ with $0.1 \times$ SSC-DTT for $30 \mathrm{~min}$ before cooling in $0.1 \times$ SSC. Sections were dehydrated in graded ethanols, air dried, and exposed to K5 nuclear emulsion (Ilford Ltd, Moberley, UK) for 2 weeks at $4{ }^{\circ} \mathrm{C}$.

\section{Histology and immunocytochemistry}

Tissue sections were dewaxed in Histoclear (National Diagnostics, Hessel, Hull, UK), rehydrated through a graded ethanol series (100\%, 95\% and 70\%) and washed in Tris-buffered saline (TBS) (0.1 M Tris- $\mathrm{HCl}(\mathrm{pH} 7.6)$ and $0.85 \% \mathrm{NaCl}$ ) for $2 \times 5 \mathrm{~min}$. Antigen retrieval procedures were necessary for exposure of all epitopes, and this was achieved by microwaving sections in $0.01 \mathrm{~mol} / \mathrm{l}$ citrate buffer ( $\mathrm{pH}$ 6.0) on full power for $3 \times 5 \mathrm{~min}$. Sections were placed in an Autostainer (Dako, Ely, UK) and incubated with the appropriate primary antibodies as follows: (a) monoclonal mouse antihuman Ki67 at a 1:100 dilution (Clone MIB-1: DakoCytomation, Ely, UK); (b) polyclonal rabbit anti-Bax at a 1:50 dilution (Santa Cruz Biotechnology, Heidelberg, Germany); or (c) polyclonal rabbit antiMcl-1 at a 1:50 dilution (Serotec, Oxford, UK) for $30 \mathrm{~min}$. Negative controls were performed by replacing the primary antibodies with non-specific mouse or rabbit IgG. Antibody binding was visualised by the ChemMate peroxidase/DAB detection system (Dako), and all sections were counterstained with haematoxylin Z (Cellpath, Hemel Hampstead, UK).

\section{Quantification by image analysis}

The immunohistochemistry results, for each marker, in the tissue collected at day 110 of gestation, were independently visually scored on a four-point arbitrary intensity scale by an operator 'blind' to the treatments. The quantification of expression was separated into primordial follicle staining, granulosa staining and vascular (endothelial and perivascular) staining. The immunohistochemical results in the tissue collected at days 50 and 65 of gestation were 
quantified by computer-aided image analysis. The system comprised an Olympus microscope $(\times 20$ objective; New Hyde Park, NY, USA) and digital camera (Hamamatsu, Bridgewater, NJ, USA) connected to a computer running Image-Pro Plus software (Media Cybernetics, Silver Spring, MD, USA). Quantification was conducted over six randomly selected fields of view, after which the mean and standard error had stabilised. The total area of positively stained cells (brown colour) was measured and expressed as a percentage of the total cellular area.

\section{Statistical analysis}

Image data were analysed by Excel or Genstat software. Data were tested for normal distribution and groups compared by one-way or two-way ANOVA and standard posthoc $t$-tests where appropriate. Where appropriate, data were also analysed by three-factor ANOVA for level of feeding in periods 1 ( $0-30$ days), 2 (31-65 days) and 3 (66-110 days). Data not normally distributed were analysed by the Kruskall-Wallis one-way ANOVA and between-group comparisons by the Mann-Whitney $U$ test.

\section{Results}

\section{Maternal live-weight gain and body condition}

Since the changes in live weight were largely a reflection of altered gut fill, the changes recorded did not provide a meaningful measure of nutritional state. However, the changes in body condition score in the respective subgroups by the time of slaughter reflected the type and duration of nutritional treatments applied. By 50 days' gestation, the mean ( \pm S.E.M.) condition score of the first slaughter group of ewes had changed from $2.46 \pm 0.02$ at mating to $2.46 \pm 0.06(\mathrm{HH}), \quad 2.34 \pm 0.05 \quad(\mathrm{LH})$, $2.28 \pm 0.06(\mathrm{HL})$ and $2.28 \pm 0.06(\mathrm{LL})$. Similarly, in the group slaughtered at 65 days, mean scores had changed from $2.44 \pm 0.03$ at mating to $2.45 \pm 0.06(\mathrm{HH})$, $2.40 \pm 0.04(\mathrm{LH}), 2.40 \pm 0.06(\mathrm{HL})$ and $2.31 \pm 0.03(\mathrm{LL})$. Scores in animals of the four nutrient-restricted groups in the final study declined from $2.46 \pm 0.02$ at mating to $2.41 \pm 0.04 \quad(\mathrm{HHH}$ control), $2.38 \pm 0.03 \quad(\mathrm{LHH})$, $2.32 \pm 0.06(\mathrm{HLH}), 2.20 \pm 0.04(\mathrm{HHL})$ and $1.93 \pm 0.05$ (LLL) at 110 days.

At days 50 and 65, the numbers of single/twin pregnancies in the respective subgroups were as follows: $\mathrm{HH}: 3 / 0$ and $1 / 4$; LH: $1 / 5$ and $2 / 2$; HL: $1 / 2$ and $1 / 5 ; \mathrm{LL}: 0 / 3$ and $1 / 3$. At day 110 , numbers of single/twin pregnancies were as follows: $\mathrm{HHH}$ : 3/2; $\mathrm{LHH}: 3 / 5$; $\mathrm{HLH}$ : 2/6; HHL: 2/4; LLL: 2/6. As we have previously reported (Rae et al. 2001), there was no effect of litter size on mean fetal mass or mean fetal ovarian masses, and no significant interaction between them.

\section{Immunolocalisation of fetal ovarian Ki67, Bax and Mcl-1 at days 50, 65 and 110 of gestation}

At days 50 and 65, Ki67, a measure of cell proliferation, was localised to the developing germ cells in the peripheral region of the fetal ovary (Fig. 1a: day 50; d: day 65). Image analysis (control animals only) indicated that the number of Ki67-positive cells remained consistent between these gestational ages (Fig. 2a). In day-110 fetal ovaries, Ki67-positive cells were sparse and localised to the granulosa cells of primordial, primary and more advanced follicles as well as to the ovarian stroma (Fig. $1 \mathrm{~g})$. The greater diversity of follicles at day 110 precluded the inclusion of these samples from the image analysis of the more homogeneous day 50 and 65 ovaries. Negative controls using non-specific mouse IgG in place of the primary antibody showed no staining.

At day 50, the apoptosis regulatory gene products Bax and $\mathrm{Mcl}-1$ were immunolocalised to the nests of developing oogonia (Fig. 1b: Bax, c: Mcl-1). In the day-65 fetal ovary, Bax and Mcl-1 remained localised to the oogonia. However, those oocytes with condensed nuclei, indicative of meiotic arrest, were immunonegative for both gene products (Fig 1e: Bax, f: Mcl-1). Numbers of Bax-immunopositive cells were significantly lower at day 65 than day $50(P<0.05$, Mann-Whitney $U$ test $)$, whereas no differences were observed with Mcl-1 (Fig 2b: Bax, c: Mcl-1). At day 110 , Bax was predominantly localised to the granulosa cells of primordial and more advanced follicles (Fig. $1 \mathrm{~h})$, and Mcl-1 was localised to oocytes at all developmental stages (Fig. 1i). Low-level Mcl-1 immunostaining was also observed in the granulosa cells. Negative controls using non-specific rabbit $\lg G$ in place of the primary antibody showed no staining.

\section{Detection of Mcl-1 and Bax mRNA by in situ hybridisation}

Sections of day-110 fetal ovaries were subjected to in situ hybridisation with Bax and Mcl-1 riboprobes. Close examination of these sections under light-field conditions revealed that both Bax (Fig. 3a) and Mcl-1 (Fig. 3b) mRNAs were localised predominantly to the developing follicles. Negative control sections incubated with sense riboprobes (Fig. 3c: Bax, d, Mcl-1) showed no signal above background levels. The specific activities of the Mcl-1 and Bax anti-sense RNA probes were $6.40 \times 10^{8}$ (sense: $9.49 \times 10^{8}$ ) and $7.98 \times 10^{8}$ (sense: $1.59 \times 10^{9}$ )

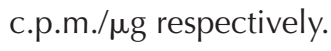

\section{Effects of maternal undernutrition on fetal ovarian Ki67, Bax and Mcl-1}

In slaughter group 1 (day 50), comparison of $\mathrm{HH}, \mathrm{HL}, \mathrm{LH}$ and LL subgroups did not reveal any significant differences in Ki67, Bax or Mcl-1 immunostaining (Fig. 4a: Ki67, c: Bax, e: Mcl-1). In slaughter group 2 (day 65), analysis by two-way ANOVA showed that undernutrition during the 

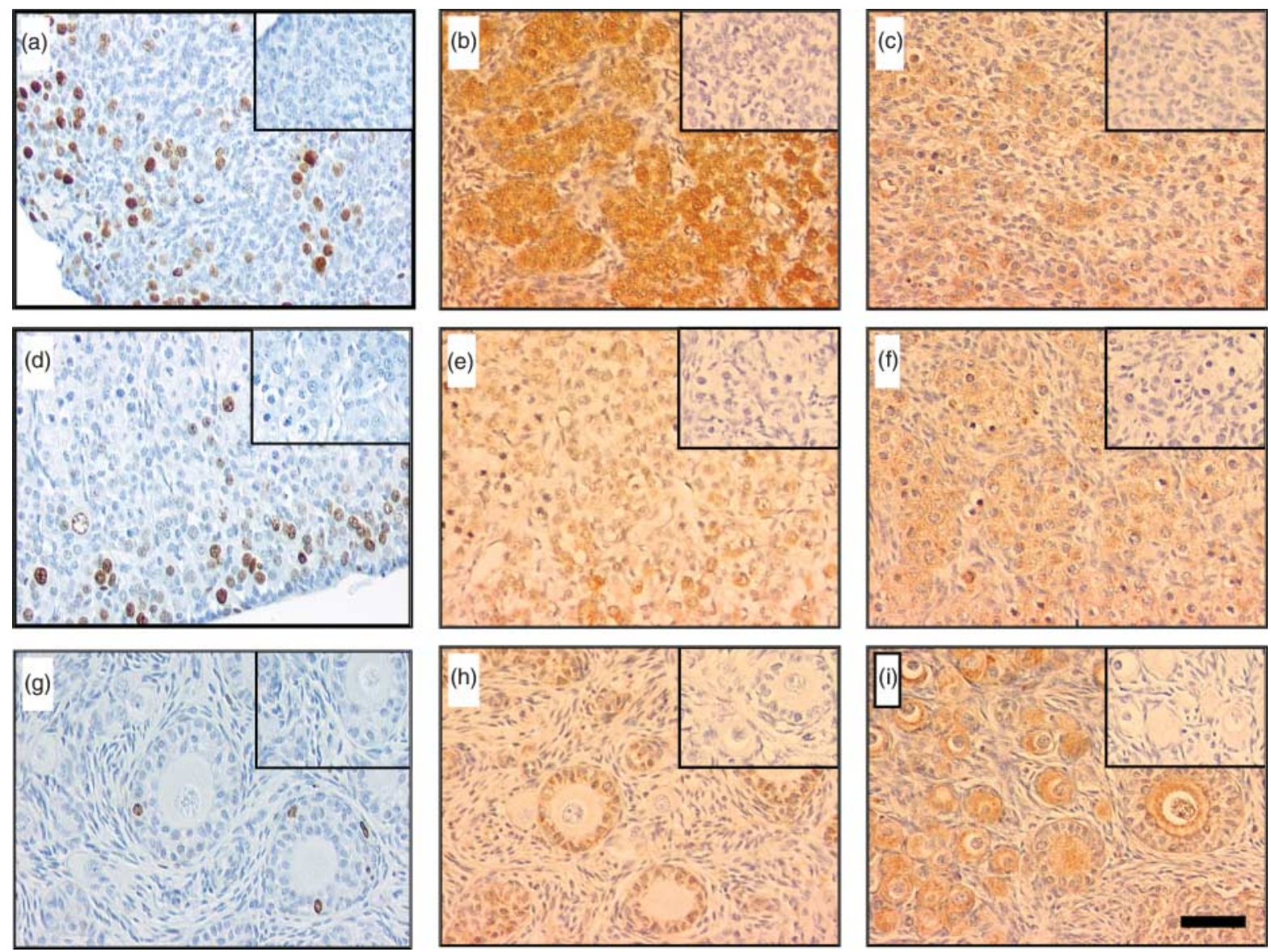

Figure 1 Immunolocalisation of markers of proliferation and apoptosis in ovaries of sheep fetuses at days 50 (a-c), 65 (d-f) and 110 (g-i) of gestation. The proliferation marker Ki67 was localised to peripheral germ cells at days 50 (a) and 65 (d). At day 110, Ki67 staining was sparse and localised mostly to granulosa and stromal cells (g). Bax (proapoptosis) and its antagonist Mcl-1 were colocalised to the nests of oogonia at day 50 (b: Bax; c: Mcl-1). At day 65, both Bax (e) and Mcl-1 (f) remained localised to the oogonia, but those in meiotic arrest (condensed nuclei) were negative for both gene products. At day 110, Bax was predominantly localised to the granulosa cells (h) and Mcl-1 to oocytes at all developmental stages (i). Scale bar $=50 \mu \mathrm{m}$. Inset $=\lg G$ negative control.

first period of $0-30$ days significantly reduced Ki67 staining $(P<0.05)$ (Fig. 4b). There was, however, no effect of undernutrition during the second period of 31-65 days. With respect to the proapoptotic gene product, Bax, twoway ANOVA showed no significant differences. However, there was a trend toward higher Bax in the three nutritionally perturbed groups, and direct comparison between the controls and animals underfed from days 30 to 65 indicated a possible relationship between underfeeding and increased ovarian Bax (HL subgroup, $P<0.05$ ) (Fig. 4d). Mcl-1 was not affected by any period of maternal undernutrition at days $0-65$ of gestation (Fig. 4e and f).

In slaughter group 3 (day 110), a three-factor ANOVA model was fitted to the data, with terms for diet in periods 1 (0-30 days), 2 (31-65 days) and 3 (66-110 days). Ki67 staining of the primordial follicles was not affected by period of underfeeding or by group (Fig. 5a). In contrast, numbers of Ki67-positive granulosa cells were significantly increased by diet during period 1 ( $0-30$ days) as compared with animals underfed from 30 to 65 days or 65 to 110 days, or normally fed throughout $(P<0.05)$ (Fig. 5b).

Analysis of day-110 fetal ovarian Bax revealed a significant group effect with respect to the primordial follicles and the granulosa cells $(P<0.01$ for each variable: oneway ANOVA). Both primordial (Fig. 5c) and granulosa cell Bax (Fig. 5d) was significantly increased in ovaries from mothers underfed from day 0 to 110 (primordial: $P<0.001$, granulosa: $P<0.01$ : post-hoc $t$-test). Granulosa cell Bax (Fig. 5d) was also significantly increased when maternal underfeeding was limited to days 65-110 $(P<0.05$ : post-hoc $t$-test), but not $0-30$ or $31-65$ days. A significant group effect was also observed with respect to Mcl-1 staining of the primordial follicles (Fig. 5e) $(P<0.01$ : one-way ANOVA), but not the granulosa cells (Fig. 5f). Primordial follicle Mcl-1 (Fig. 5e) was significantly increased in animals underfed from 0 to 110 days $(P<0.05$ : post-hoc $t$-test $)$ and in those underfed from 65 to 110 days $(P<0.001$ : post-hoc $t$-test), but not in the other subgroups. 

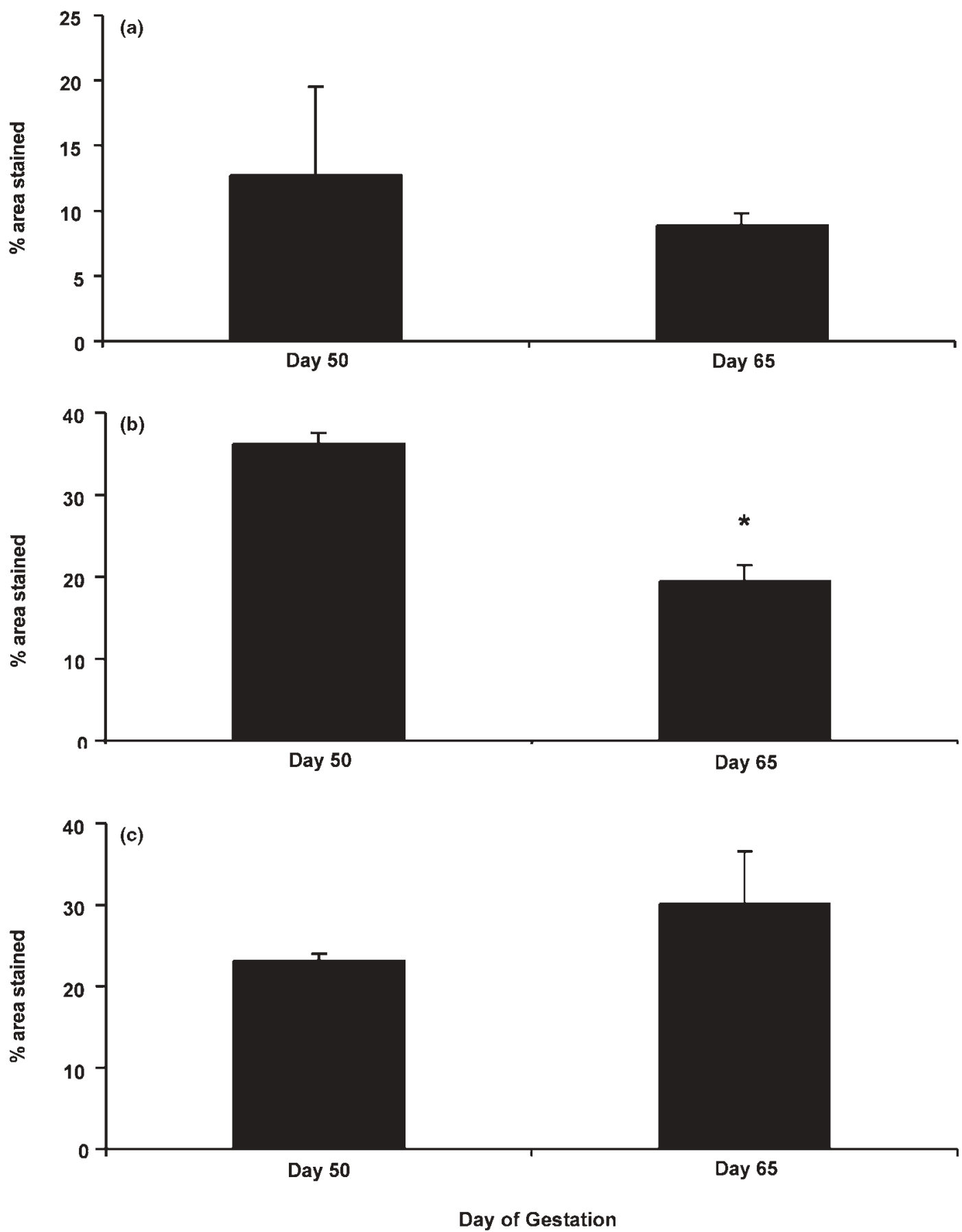

Figure 2 Changes in Ki67, Bax and Mcl-1 percentage of nucleated area stained between days 50 and 65 of gestation of control animals. No significant differences in Ki67 (a) or Mcl-1 (c) were observed. Bax (b) was significantly reduced between 50 and 65 days $\left({ }^{*} P<0.05\right)$. Values are expressed as means \pm S.E.M.

Effects of maternal undernutrition on Bax and Mcl-1 in the fetal ovarian vasculature

In day-110 fetal ovary sections from control-fed animals, Bax and Mcl-1 were localised to the fetal ovary vasculature. Bax was predominantly localised to perivascular areas (Fig. 6a), and Mcl-1 was predominantly endothelial
(Fig. 6b). Some very sporadic Ki67 endothelial staining was also noted (not shown).

With respect to Bax endothelial staining, a significant group effect was observed $(P<0.05$ : one-way ANOVA), and staining was significantly increased in the group restricted from days 0 to $110(P<0.01$ : post-hoc $t$-test $)$ 

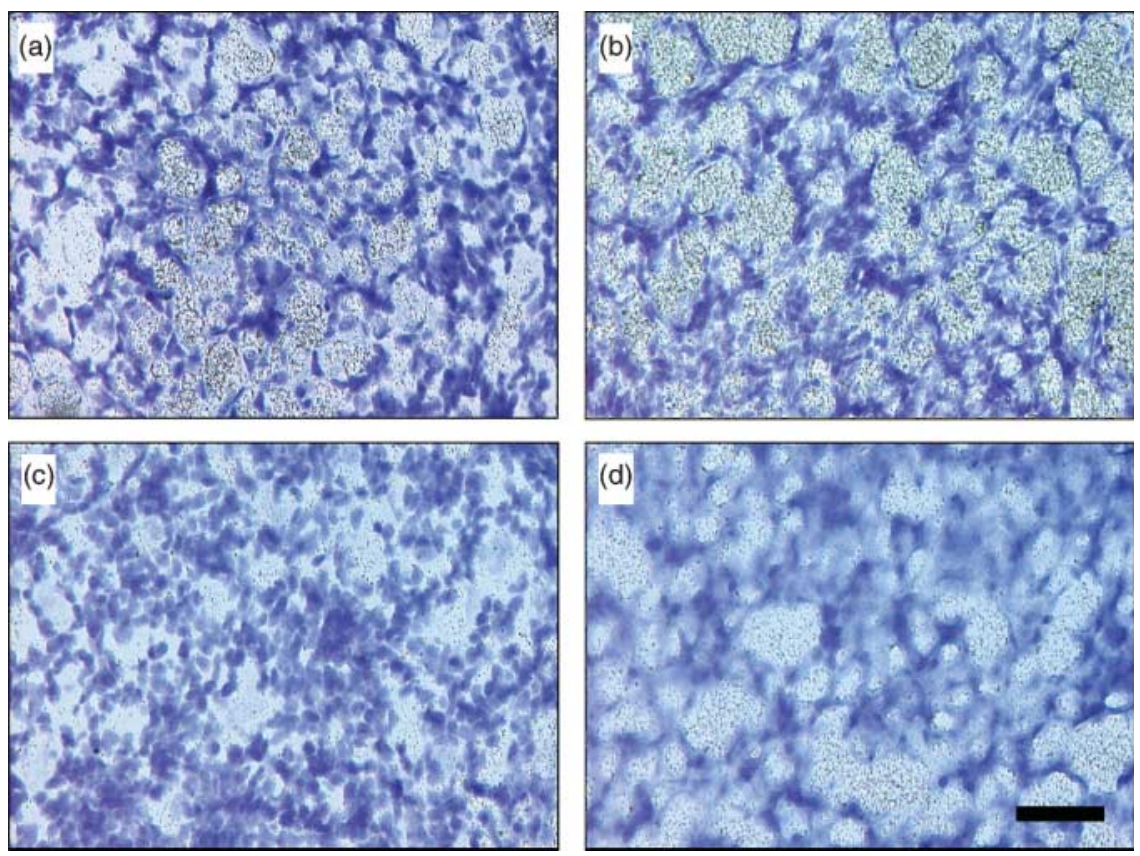

Figure 3 Expression of Bax and Mcl-1 mRNA in day-110 ovine fetal ovary by in situ hybridisation with

${ }^{35}$ S-labelled complementary RNA to ovine Bax and Mcl-1. (a and b) Lightfield microscopy images showing predominant hybridisation of Bax and Mcl-1 anti-sense probes to the developing follicles. (c and d) Light-field sense controls for Bax and $\mathrm{Mcl}-1$ respectively. Scale bar $=50 \mu \mathrm{m}$.

(Fig. 7a). In addition, three-factor ANOVA revealed a significant increase in endothelial Bax in response to underfeeding from 66 to 110 days (period 3: $P<0.05$ ). This is shown histologically in Fig. 6c, in which staining can be seen in the endothelial cell layer in addition to the perivascular area. In the control section (Fig. 6a), only perivascular staining can be seen. Perivascular Bax showed a significant group effect $(P<0.01$ : Kruskal-Wallis one-way ANOVA), but no significant differences (MannWhitney $U$ test) were found between the control $\mathrm{HHH}$ group and those groups nutritionally perturbed (Fig. 7b). With respect to the endothelial Mcl-1 staining, a one-way
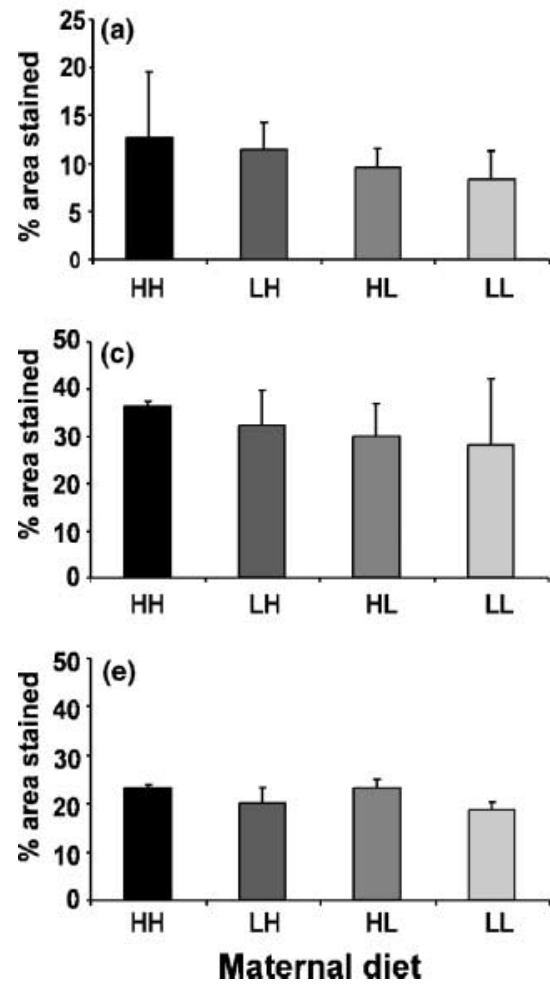

www.reproduction-online.org
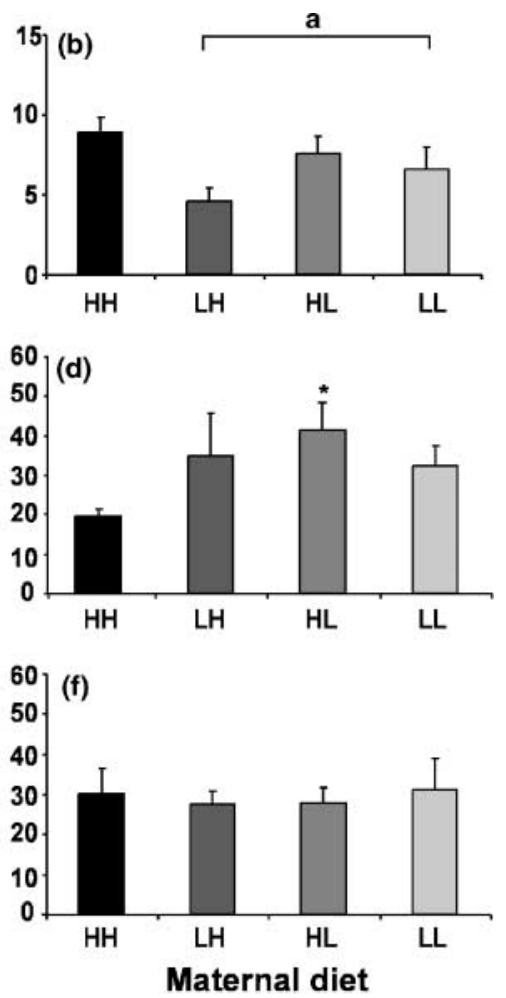

Figure 4 Effects of maternal undernutrition on percentage of fetal ovarian Ki67, Bax and Mcl-1 at days 50 and 65 of gestation. Groups of ewes $(n=12-19)$ were fed rations providing either $100 \%$ (high; H) or $50 \%$ (low; L) of energy requirements for live-weight maintenance. Control ewes were fed $\mathrm{H}$ ration from mating until slaughter at days 50 or $65(\mathrm{HH})$, whereas ewes of other groups were fed as follows. LH: L ration from mating to day 30 and then $\mathrm{H}$ ration from days 31 to 50 or 65 of gestation; $\mathrm{HL}$ : $\mathrm{H}$ ration from mating to day 30 of gestation and then $L$ ration from days 31 to 50 or 65 of gestation; LL: $\mathrm{L}$ ration from mating to slaughter at day 50 or 65 of gestation. Results are expressed as percentage of the total nucleated area of the fetal ovary. ( $a$ and b) Fetal ovarian Ki67 at days 50 and 65 respectively; (c and d) fetal ovarian Bax at days 50 and 65 respectively; (e and f) fetal ovarian Mcl-1 at days 50 and 65 respectively. Values are expressed as means \pm S.E.M. $\mathrm{a}=$ significant effect of undernutrition during the first period of $0-30$ days: $P<0.05$. Significant differences relative to $\mathrm{HH}$ control values within experiment: ${ }^{*} P<0.05$. 
Primordial follicles
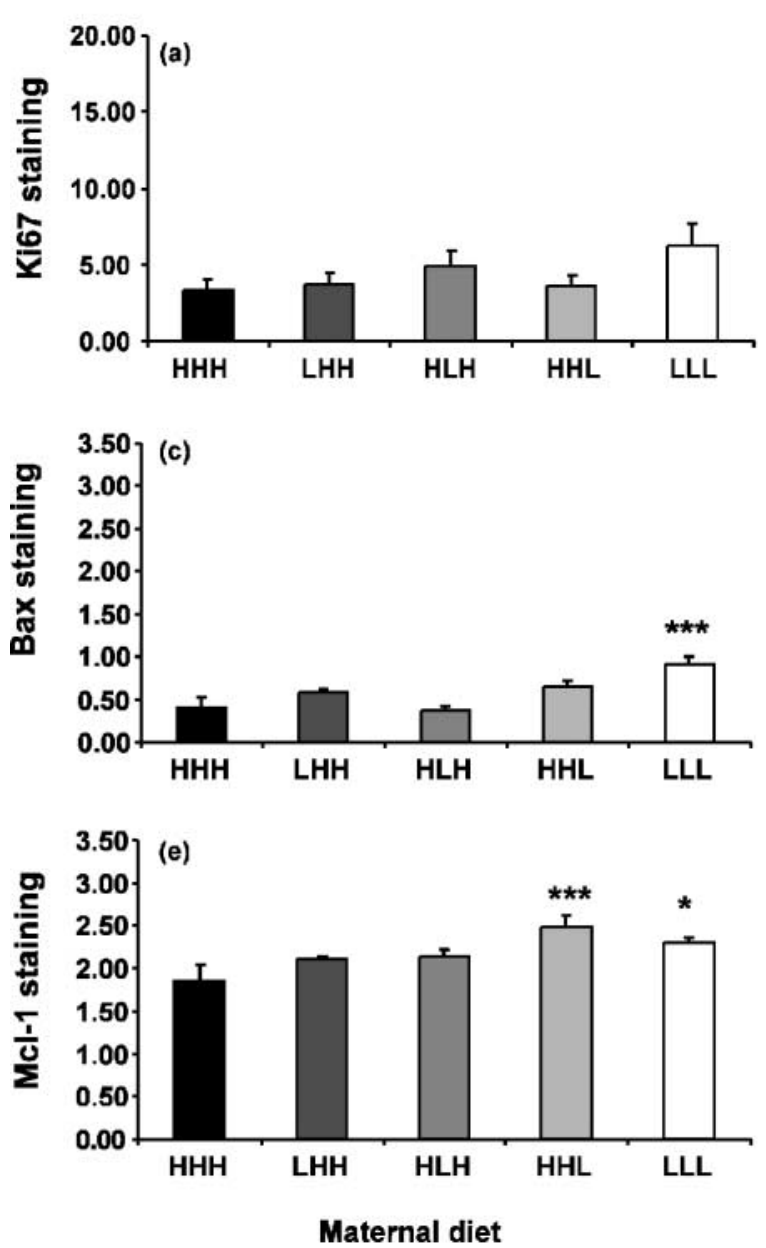

Granulosa cells
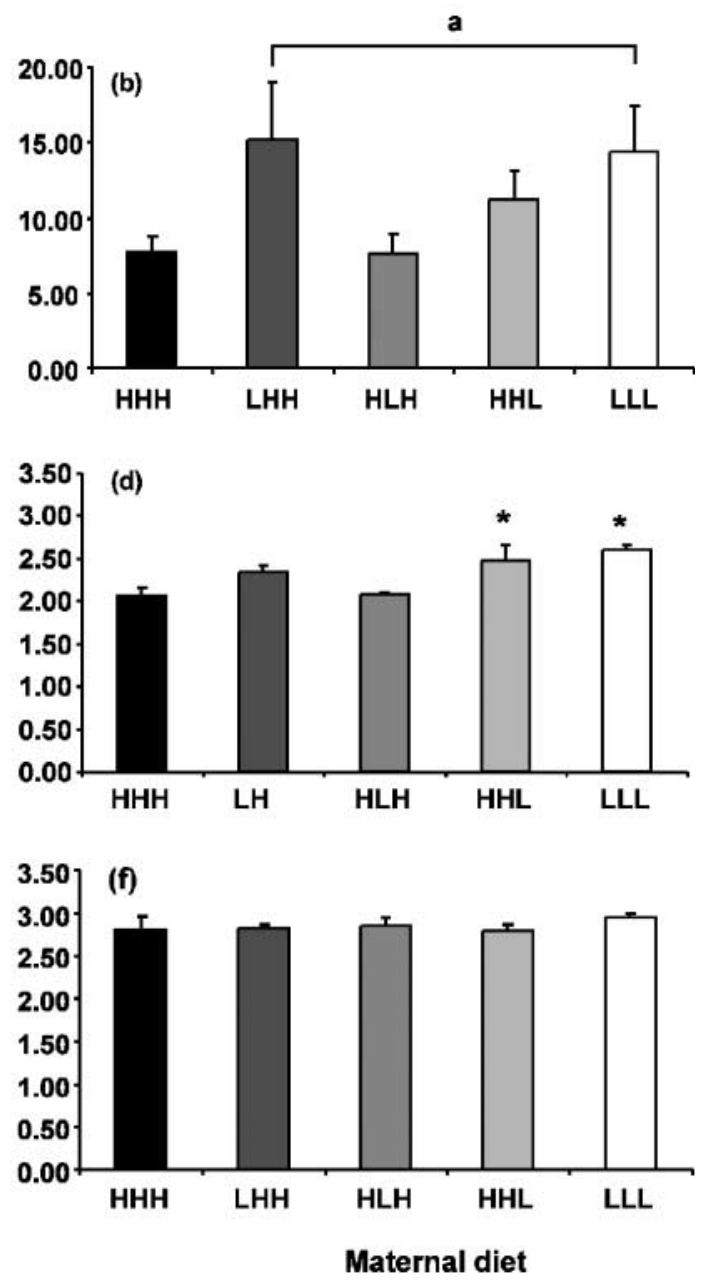

Figure 5 Effects of maternal undernutrition on ovarian Ki67, Bax and Mcl-1 at day 110 of gestation. Groups of ewes $(n=11-19)$ were fed rations providing either $100 \%$ (high; $\mathrm{H}$ ) or $50 \%$ (low; L) of energy requirements for live-weight maintenance. Control ewes were fed the $\mathrm{H}$ ration from mating until slaughter at day $110(\mathrm{HHH})$, whereas ewes of other groups were fed as follows. $\mathrm{LHH}$ : $\mathrm{L}$ ration from mating to day 30 and then $\mathrm{H}$ ration from day 31 to day 110 of gestation; $\mathrm{HLH}$ : $\mathrm{H}$ ration from mating to day 30 of gestation, $\mathrm{L}$ ration from day 31 to day 65 , and $\mathrm{H}$ ration from day 66 to 110; HHL: H ration from mating to day 65 and L ration from day 66 to 110; LLL: L ration from mating to slaughter at day 110 of gestation. For each marker, results were independently visually scored on a four-point arbitrary intensity scale by an operator 'blind' to the treatments. (a and b) Ki67 staining of primordial follicles and granulosa cells respectively; (c and d) Bax staining of primordial follicles and granulosa cells respectively; (e and f) Mcl-1 staining of primordial follicles and granulosa cells respectively. Values are expressed as means \pm S.E.M. a $=$ significant effect of undernutrition during the first period of $0-30$ days: $P<0.05$. Significant differences relative to $\mathrm{HHH}$ control values within experiment: ${ }^{*} P<0.05$; ${ }^{* *} P<0.01 ;{ }^{* *} P<0.001$.

ANOVA indicated a $P$ value of 0.06 . It was noted that fetal ovaries from mothers underfed from day 0 to 110 had the highest levels of Mcl-1 (Fig. 7c). Indeed, comparing this underfed group to the controls indicated a possible relationship between underfeeding and endothelial Mcl-1 $(P<0.05: \quad t$-test). In addition, the three-factor ANOVA revealed a significant increase in endothelial Mcl-1 in response to underfeeding from 0 to 30 days (period 1: $P<0.05$ ). Perivascular staining for $\mathrm{Mcl}-1$ was observed only in animals underfed from 0 to 110 days (Fig. 6d and Fig. 7d) $(P<0.05$ cf controls; Kruskal-Wallis one-way ANOVA).

\section{Discussion}

There is considerable evidence that reduced maternal nutrient intake during pregnancy can adversely affect reproductive function in adult life (Rhind 2004). However, the biological mechanisms underpinning this 'programming of adult reproductive dysfunction' are largely unknown. In the sheep, it has been shown previously that underfeeding pregnant adult sheep for the first two-thirds of pregnancy delays follicular development at day 110 and reduces ovulation rates in the adult female offspring (Rae et al. 2001, 2002). In addition, measurements at 

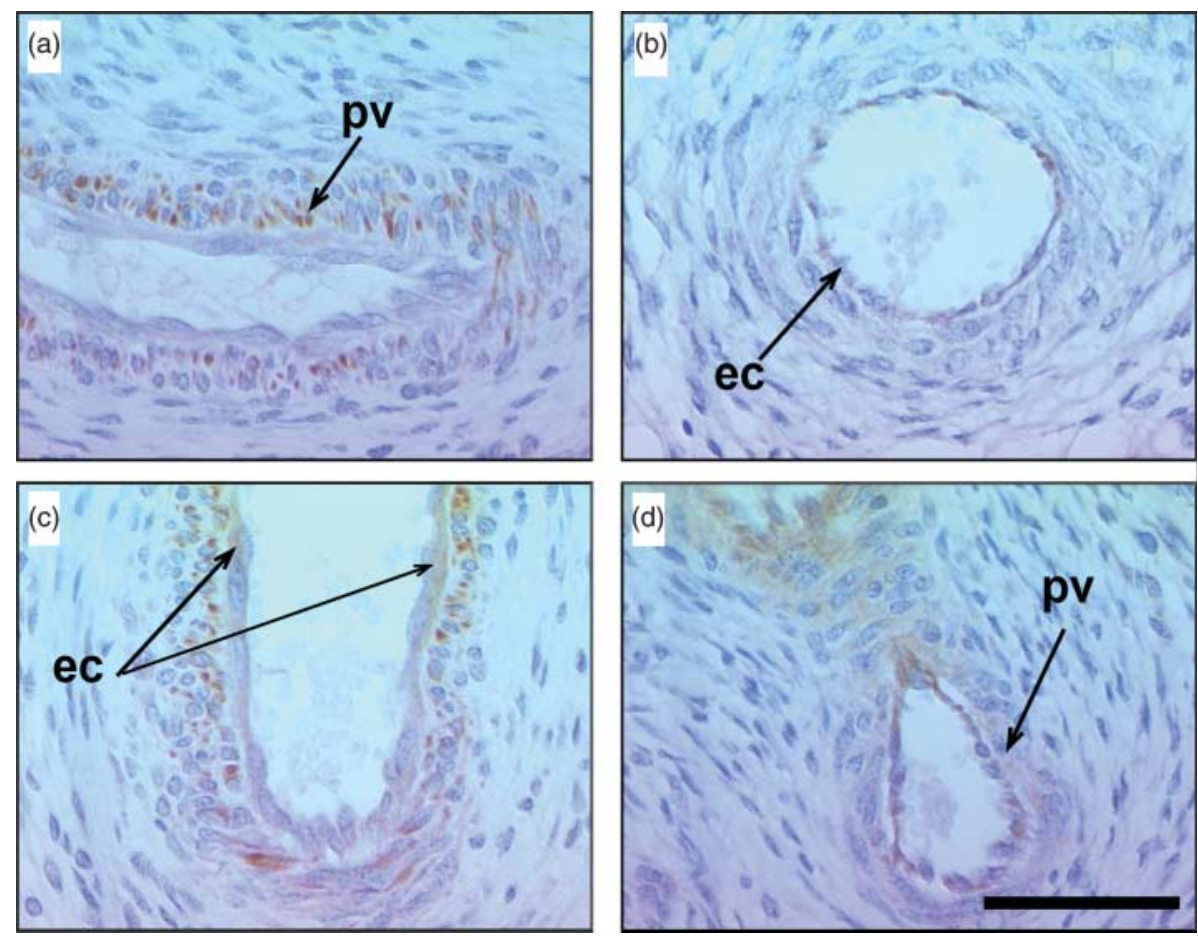

Figure 6 Immunolocalisation of Bax and $\mathrm{Mcl}-1$ in the vasculature of day110 sheep fetal ovaries. In control tissues, Bax was localised to perivascular cells (pv) (a) and Mcl- 1 to endothelial cells (ec) (b). In ovaries from animals underfed from mating to day 110 of gestation, Bax was detectable in the endothelial cells as well as the perivascular cells (c), and Mcl-1 in perivascular areas as well as the endothelial cells (d). Scale bar $=50 \mu \mathrm{m}$.
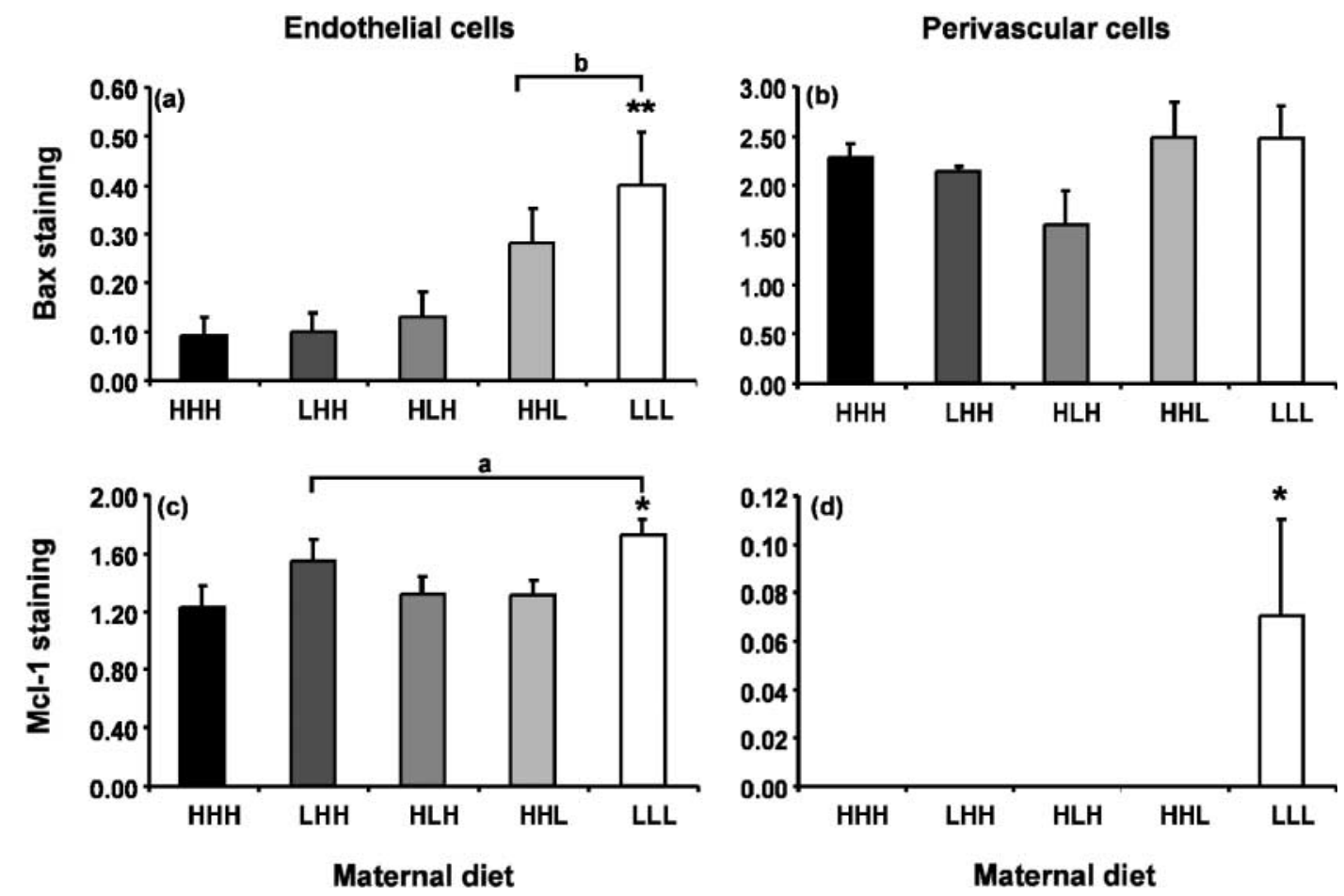

Figure 7 Effects of maternal undernutrition on Bax and Mcl-1 in the vasculature of day-110 sheep fetal ovaries. Groups of ewes $(n=11-19)$ were fed rations providing either $100 \%$ (high; $\mathrm{H}$ ) or $50 \%$ (low; L) of energy requirements for live-weight maintenance. Animal groups are as defined in Fig. 5 legend and in Materials and Methods. For each marker, results were independently visually scored on a four-point arbitrary intensity scale by an operator 'blind' to the treatments. (a and b) Bax staining of endothelial and perivascular cells respectively. Note the gradual increase in Bax staining as the window of undernutrition moves from early to mid- to late stages of the 110-day period. (c and d) Mcl-1 staining of endothelial and perivascular cells respectively. $a=$ significant effect of undernutrition during the first period of $0-30$ days:

$P<0.05 ; b=$ significant effect of undernutrition during the third period of $66-110$ days: $P<0.05$. Values are expressed as means \pm S.E.M. Significant differences relative to $\mathrm{HHH}$ control values within experiment: ${ }^{*} P<0.05 ;{ }^{* *} P<0.01$. 
110 days' gestation have shown that maternal fetal undernutrition limited to periods corresponding to the times at which fetal ovarian differentiation, growth, meiosis or folliculogenesis occur also reduces follicle development beyond the primordial stage (Rae et al. 2001). Thus, it is clear that different developmental stages and physiological mechanisms are sensitive to maternal undernutrition.

Fetal ovarian proliferation was assessed with an antibody specific for the Ki67 antigen, and immunoreactivity was observed almost exclusively in the germ cells at days 50 and 65. Our previous studies with an anti-PCNA (proliferating cell nuclear antigen) antibody also revealed immunoreactivity in day-50 germ cells; however, at day 65, PCNA was localised predominantly to the somatic cells (Rae et al. 2001). This difference is likely to be attributable to the specificities of the two antibodies. PCNA is involved in DNA repair synthesis as well as DNA replication, and it has a half-life in excess of $20 \mathrm{~h}$ (McCormick \& Hall 1992, Yu et al. 1992). Consequently, it may be detected in non-cycling cells in the Go phase of the cell cycle. In contrast, Ki67 is expressed in all active phases of the cell cycle, is rapidly degraded as cells become non-proliferative, and is not involved in DNA repair (Scholzen \& Gerdes 2000). Thus, Ki67 immunostaining on day-65 fetal ovaries was more specifically linked to proliferating cells.

Data presented in this paper demonstrate mRNA and protein expression of the proapoptotic gene, Bax, and its antagonist, Mcl-1, in the developing ovine fetal ovary. Both gene products were localised to the germ cells at days 50 and 65, although day-65 germ cells in meiotic arrest were negative. In the day-110 fetal ovary containing more advanced follicles, Mcl-1 was predominantly localised to the oocytes and Bax to the granulosa cells. These findings support previous studies on rodent and human fetal ovarian Mcl-1 (Sano et al. 2000, Hartley et al. 2002). Interestingly, in the mouse fetal ovary, Bax has been immunolocalised predominantly to degenerating oocytes in midgestation and to some healthy oocytes in late gestation (Felici et al. 1999). In the same study, Bax was found to be downregulated at the time of birth when oocyte meiotic arrest occurs in the mouse. This supports observations made in the present study, since ovine fetal oocytes undergoing meiotic arrest are negative for the apoptosis regulatory genes. In the sheep, meiotic arrest occurs earlier in gestation than in the mouse, and in this regard is more comparable to man (Speed 1982, McNatty et al. 1995).

In the present study, we have shown that in the day-65 fetal ovary, Ki67 immunostaining of germ cells, indicative of cell proliferation, is reduced when maternal food intake is restricted from 0 to 30 days of gestation. This indicates that the development of the germ cells may be delayed and may account for our earlier report of reduced numbers of oocytes entering meiotic arrest in the same subgroup (Rae et al. 2001). In addition, restricted maternal food intake from 0 to 30 days increased the number of Ki67-positive granulosa cells at day 110. Thus, the more advanced fetal ovary is affected differently. Interestingly, the cell lineage that triggers follicle degeneration is reported to change depending on the stage of follicle development. At the primordial follicle stage, oocyte apoptosis triggers atresia, whereas at more advanced follicular stages, granulosa cell apoptosis is believed to be responsible (reviewed in Kim \& Tilly 2004). The upregulated granulosa cell proliferation in this study may therefore be a survival strategy.

In contrast to ovarian proliferative activity, Bax and Mcl-1 were generally sensitive to later windows of undernutrition. The expression of both genes was increased in the primordial follicles after nutritional restriction from 0 to 110 days of gestation. In addition, nutritional restriction from 66 to 110 days increased primordial follicle Mcl-1, and granulosa cell Bax was increased in both groups. Similarly, in the vasculature, endothelial Bax was also sensitive to later windows of undernutrition (0-110 and 66110 days), although, intriguingly, endothelial Mcl-1 was increased in response to underfeeding from 0 to 30 days. Overall, nutritional restriction from 0 to 30 days appears to affect the development of germ cells, probably delaying the onset of meiosis a month later. In contrast, restriction from 66 to 110 days, or from 0 to 110 days, alters apoptosis regulatory genes in the follicle and granulosa cells, probably affecting folliculogenesis directly. Increased Bax in the vasculature may also affect this process.

In man and other mammals, a majority of the oocytes present at midgestation degenerate during embryonic, fetal and early postnatal life. A number of studies have shown that this occurs by apoptosis; in man, the overall loss is estimated to be 99.9\% (Coucouvanis et al. 1993, Ratts et al. 1995, De Pol et al. 1997). Thus, perturbation of the expression of the genes that regulate this process may have a substantial impact on adult offspring fertility. Studies of the human fetal ovary have shown that genes of the $\mathrm{Bcl}-2$ family are expressed throughout the second trimester, indicating that they are likely to be involved in this process (Hartley et al. 2002). Indeed, a survival/antiapoptotic role for oocyte $\mathrm{Mcl}-1$ has been suggested with respect to the human fetal ovary, particularly at the time of germ cell-somatic cell interaction required for the formation of the primordial follicle (Hartley et al. 2002). In the undernourished pregnant ewe, the increased incidence of DNA damage that has been reported in midgestation fetal ovaries (Murdoch et al. 2003) was associated with upregulation of the tumour suppressor/cell cycle modulator p53, the antiapoptotic factor $\mathrm{Bcl}-2$ and base excision repair (polymerase $\mathrm{B}$ ). It was proposed that expression of these genes alters in response to DNA damage, induces cell-cycle arrest (p53) and prevents apoptosis (Bcl-2), while allowing DNA repair (polymerase B) to occur. In the present study, fetal nutrient restriction increased both Mcl-1 (antiapoptosis) and its antagonist Bax in day-110 primordial follicle oocytes. Thus, we 
postulate that the increased oocyte Mcl-1 in undernourished ewes that we observed may contribute to oocyte survival. The expression of Mcl-1 is upregulated by growth factors such as stem cell factor (SCF), a factor known to be important for germ-cell survival (Huang et al. 2000). This has led to the suggestion that the antiapoptotic environment induced by Mcl-1 is SCF/c-kit dependent. The effects of nutrient restriction on fetal ovarian SCF have not been investigated.

The proapoptotic $\mathrm{Bcl}-2$ family member, Bax, has been shown to drive oocyte loss and granulosa cell development in mouse and human fetal ovaries; indeed, the direct application of Bax to isolated oocytes induces apoptosis (Vaskivuo et al. 2001, Matikainen et al. 2002). Bax knockout mice exhibit a threefold increase in the number of primordial follicles in their ovarian reserve, compared with wild-type controls, and exhibit unusual atretic follicles with excess granulosa cells (Knudson et al. 1995, Perez et al. 1999). Moreover, in the mouse, the balance between prosurvival $\mathrm{Bcl}-\mathrm{x}$ and $\mathrm{Bax}$ has been shown to be critical for normal fetal germ-cell survival (Rucker et al. 2000). The current observation of increased granulosa cell Bax expression in underfed animals may therefore account for the reduction in the number of follicles that develop sufficient granulosa cell layers to progress beyond the primordial stage. Indeed, in the human fetal ovary, the survival of growing follicles is thought to be primarily determined by granulosa cell apoptosis (Vaskivuo et al. 2001).

Bax and Mcl-1 are two members of a large family of apoptosis-regulating genes. For example, Mcl-1 interacts with the proapoptotic protein Bok $(\mathrm{BCl}-2$ ovary-related killer gene). However, the expression of this factor in the fetal ovary has not been investigated (Hsu et al. 1997). In addition there are other proapoptotic genes such as Bclxs, Diva/Boo, Bad and Bim, all of which are expressed in adult germ or granulosa cells (reviewed in Kim \& Tilly 2004). Nevertheless, given the predominance of Mcl-1 in the developing oocyte and the altered ovary development in Bax knockout mice, we suggest that the changes in these genes observed in this study have an important role in fetal ovary development.

In conclusion, we have shown that the developing sheep fetal ovary is sensitive to maternal undernutrition imposed during different windows of gestation and thus different developmental stages. Underfeeding the mother for the first 30 days of gestation reduced germ-cell proliferation at day 65 but increased granulosa cell proliferation at day 110 . In contrast, underfeeding from 65 to 110 days or from 0 to 110 days generally alters the expression of genes that regulate apoptosis. Both mechanisms are likely to contribute to the reduced number of ovarian primordial follicles that characterise this underfeeding model. In view of the sensitivity of the fetal ovary to environmental influences, an understanding of the impact of altered nutrition on ovarian development may facilitate future intervention strategies designed to protect the oocyte pool.

\section{Acknowledgements}

The authors wish to thank Dr G Horgan (Biomathematics and Statistics Scotland) for statistical assistance, and the Scottish Executive Environment and Rural Affairs Department (SEERAD) for financial support. The laboratory work was supported by Portuguese government grant SFRH/BPD/11645/2002, awarded to Professor L P Andrade. The authors declare that there is no conflict of interest that would prejudice the impartiality of this scientific work.

\section{References}

Baker TG 1963 A quantitative and cytological study of germ cells in human ovaries. Proceedings of the Royal Society of London. Series B: Biological Sciences (London) 158 417-433.

Coucouvanis EC, Sherwood SW, Carswell-Crumpton C, Spack EG \& Jones PP 1993 Evidence that the mechanism of prenatal germ cell death in the mouse is apoptosis. Experimental Cell Research 209 238-247.

De Pol A, Vaccina F, Forabosco A, Cavazzuti E \& Marzona L 1997 Apoptosis of germ cells during human prenatal oogenesis. Human Reproduction 12 2235-2241.

Felici MD, Carlo AD, Pesce M, Iona S, Farrace MG \& Piacentini M $1999 \mathrm{Bcl}-2$ and Bax regulation of apoptosis in germ cells during prenatal oogenesis in the mouse embryo. Cell Death and Differentiation 6 908-915.

Hartley PS, Bayne RA, Robinson LL, Fulton N \& Anderson RA 2002 Developmental changes in expression of myeloid cell leukemia-1 in human germ cells during oogenesis and early folliculogenesis. Journal of Clinical Endocrinology and Metabolism 87 3417-3427.

Hsu SY, Kaipia A, McGee E, Lomeli M \& Hsueh AJ 1997 Bok is a pro-apoptotic $\mathrm{Bcl}-2$ protein with restricted expression in reproductive tissues and heterodimerizes with selective anti-apoptotic BCl-2 family members. PNAS 94 12401-12406.

Hsueh AJ, Billig H \& Tsafriri A 1994 Ovarian follicle atresia: a hormonally controlled apoptotic process. Endocrine Reviews 15 707-724.

Huang HM, Huang CJ \& Yen JJ 2000 Mcl-1 is a common target of stem cell factor and interleukin-5 for apoptosis prevention activity via MEK/MAPK and Pl-3K/Akt pathways. Blood 96 1764-1771.

Ibanez L, Potau N, Ferrer A, Rodriguez-Hierro F, Marcos MV \& de Zegher F 2002 Reduced ovulation rate in adolescent girls born small for gestational age. Journal of Clinical Endocrinology and Metabolism 87 3391-3393.

Kim MR \& Tilly JL 2004 Current concepts in Bcl-2 family member regulation of female germ cell development and survival. Biochimica Biophysica Acta 1644 205-210.

Knudson CM, Tung KS, Tourtellotte WG, Brown GA \& Korsmeyer SJ 1995 Bax-deficient mice with lymphoid hyperplasia and male germ cell death. Science 270 96-99.

Lea RG, Hannah LT, Redmer DA, Aitken RP, Milne JS, Fowler PA, Murray JF \& Wallace JM 2005 Developmental indices of nutritionally induced placental growth restriction in the adolescent sheep. Pediatric Research 57 599-604.

Matikainen TM, Moriyama T, Morita Y, Perez GI, Korsmeyer SJ, Sherr DH \& Tilly JL 2002 Ligand activation of the aromatic hydrocarbon receptor transcription factor drives Bax-dependent apoptosis in developing fetal ovarian germ cells. Endocrinology 143 615-620.

McCormick D \& Hall PA 1992 The complexities of proliferating cell nuclear antigen. Histopathology 21 591-594.

McNatty KP, Smith P, Hudson NL, Heath DA, Tisdall DJ, O WS \& Braw-Tal R 1995 Development of the sheep ovary during fetal and early neonatal life and the effect of fecundity genes. Journal of Reproduction and Fertilty Supplement 49 123-135. 
Meikle D \& Westberg M 2001 Maternal nutrition and reproduction of daughters in wild house mice (Mus musculus). Reproduction 122 437-442.

Murdoch WJ, Van Kirk EA, Vonnahme KA \& Ford SP 2003 Ovarian responses to undernutrition in pregnant ewes, USA. Reproductive Biology and Endocrinology $\mathbf{1} 6$.

Perez GI, Robles R, Knudson CM, Flaws JA, Korsmeyer SJ \& Tilly JL 1999 Prolongation of ovarian lifespan into advanced chronological age by Bax-deficiency. Nature Genetics 21 200-203.

Rae MT, Palassio S, Kyle CE, Brooks AN, Lea RG, Miller DW \& Rhind SM 2001 Effect of maternal undernutrition during pregnancy on early ovarian development and subsequent follicular development in sheep fetuses. Reproduction 122 915-922.

Rae MT, Kyle CE, Miller DW, Hammond AJ, Brooks AN \& Rhind SM 2002 The effects of undernutrition, in utero, on reproductive function in adult male and female sheep. Animal Reproduction Science 72 63-71.

Ratts VS, Flaws JA, Kolp R, Sorenson CM \& Tilly JL 1995 Ablation of bcl-2 gene expression decreases the numbers of oocytes and primordial follicles established in the post-natal female mouse gonad. Endocrinology 136 3665-3668.

Rhind SM 2004 Effects of maternal nutrition on fetal and neonatal reproductive development and function. Animal Reproduction Science 82-83 169-181.

Rinkenberger JL, Horning S, Klocke B, Roth K \& Korsmeyer SJ 2000 Mcl-1 deficiency results in peri-implantation embryonic lethality. Genes and Devlopment 14 23-27.

Robinson JJ, Russel AJF, Treacher TT \& Kilkenny JB, 1983 Feeding the Ewe. Meat and Livestock Commission, Sheep Improvement Services.

Rucker EB 3rd, Dierisseau P, Wagner KU, Garrett L, Wynshaw-Boris A, Flaws JA \& Hennighausen L 2000 Bcl-x and Bax regulate mouse primordial germ cell survival and apoptosis during embryogenesis. Molecular Endocrinology 14 1038-1052.
Russel AJF, Doney JM \& Gunn RG 1969 Subjective assessment of body fat in live sheep. Journal of Agricultural Science $\mathbf{7 2}$ $451-454$.

Sano M, Umezawa A, Suzuki A, Shimoda K, Fukuma M \& Hata J 2000 Involvement of EAT/mcl-1, an anti-apoptotic bcl-2-related gene, in murine embryogenesis and human development. Experimental Cell Research 259 127-139.

Scholzen T \& Gerdes J 2000 The Ki-67 protein: from the known and the unknown. Journal of Cell Physiology 182 311-322.

Speed RM 1982 Meiosis in the foetal mouse ovary. I. An analysis at the light microscope level using surface-spreading. Chromosoma $85427-437$.

Vaskivuo TE, Anttonen $M$, Herva $R$, Billig $H$, Dorland $M$, te Velde ER, Stenback F, Heikinheimo M \& Tapanainen JS 2001 Survival of human ovarian follicles from fetal to adult life: apoptosis, apoptosis-related proteins, and transcription factor GATA-4. Journal of Clinical Endocrinology and Metabolism 86 $3421-3429$.

Yu CC, Woods AL \& Levison DA 1992 The assessment of cellular proliferation by immunohistochemistry: a review of currently available methods and their applications. Histochemistry Journal 24 $121-131$.

Received 13 June 2005

First decision 5 August 2005

Revised manuscript received 16 August 2005

Accepted 2 September 2005 